\title{
Healthcare Professionals' Beliefs and Attitudes Toward Home Hemodialysis
}

\author{
Belgüzar Kara ${ }^{1 *}$ and İllknur Yazıcıoğlu ${ }^{2}$ \\ ${ }^{1}$ Department of Internal Medicine Nursing, Faculty of Health Sciences, Yuksek Ihtisas University, Turkey \\ ${ }^{2}$ Gulhane School of Nursing, University of Health Sciences, Turkey
}

Submission: January 16, 2018 ; Published: February 08, 2018

*Corresponding author: Belgüzar Kara, Professor, Department of Internal Medicine Nursing, Faculty of Health Sciences, Yuksek Ihtisas University, Ankara, Turkey, Email: belguzarkara@yiu.edu.tr

\begin{abstract}
Objective: The aim of this pilot study was to assess the beliefs and attitudes of healthcare professionals toward home hemodialysis (HHD).

Methods: This cross-sectional study included 20 healthcare professionals who were working in a nephrology clinic of a training hospital in Turkey. Data were collected using a questionnaire form. Data analysis were performed using descriptive statistics.

Results: The majority of the participants $(60 \%)$ believed that more frequent or extended hemodialysis is best delivered at home. The most common perceived benefits of HHD by healthcare professionals were comfort in familiar surroundings, more time spent with family and more privacy $(100 \%)$. The most common perceived barrier to HHD by healthcare professionals was lack of appropriate home environment for hemodialysis $(90 \%)$
\end{abstract}

Conclusion: The results of this study underscore the importance of determining healthcare professionals' beliefs and attitudes about HHD for supporting them appropriately in their work.

Keywords: Attitudes; Beliefs; Healthcare professionals; Home hemodialysis

\section{Introduction}

Global interest in home hemodialysis (HHD) has been increasing recently because of its clinical benefits and flexibility [1-3]. Especially, more frequent or extended HHD is associated with survival benefits and enhanced quality of life [4-8]. It was found that conversion from conventional hemodialysis to frequent or extended hemodialysis contributes to improvement in cardiac morphology and function, as well as blood pressure parameters [9]. Nocturnal HHD is considered to be a bridge to kidney transplantation or an alternative in the absence of living donor kidney transplantation [8]. However, a limited number of studies have examined the healthcare professionals' beliefs and attitudes toward HHD [10-13]. To the our knowledge, there is no study investigating this issue among Turkish healthcare professionals. Therefore, the aim of this pilot study was to assess the beliefs and attitudes of healthcare professionals about HHD.

This cross-sectional study was performed between January 2017 and May 2017. All the healthcare professionals who were working in a nephrology clinic of a training hospital in Turkey were included in this study. Of the 22 eligible healthcare professionals, 20 ( $80 \%$ female) agreed to participate (response rate: $90.9 \%$ ). This study was approved by the Hospital Ethical Committee, and written informed consent was obtained from all of the participants. Data were collected using a questionnaire form consisting of questions regarding sociodemographic and work-related characteristics and beliefs and attitudes about HHD. Data analysis were performed using descriptive statistics.

The mean age of the study group was $37.0 \pm 7.5$ years (range $=$ 23-56), and the median duration of work in the nephrology clinic was 7.5 years. The participants consisted of three doctors (15\%), 13 nurses (65\%) and four dialysis technician (20\%). In this study, $60 \%$ of the participants were graduated from university and $15 \%$ had higher degree. The majority of the participants (90\%) believed that more frequent or extended hemodialysis enhance dialysis efficacy. Sixty percent of healthcare professionals stated that more frequent or extended hemodialysis is best delivered at home. All the healthcare professionals reported having knowledge about HHD, and 13 participants (65\%) wanted to attend scientific meetings on HHD. It is important that healthcare professionals are provided with adequate training to guide their patients in choosing dialysis modality $[1,10,12]$. Most of the healthcare professionals $(90 \%)$ stated that they would support providing 
HHD program in their unit. If the healthcare professionals or their relatives must undergo chronic hemodialysis for end-stage renal disease, approximately half of the participants (45\%) mentioned that they will firstly choose HHD.

All the healthcare professionals (100\%) reported on benefits about HHD, including comfort in familiar surroundings, more time spent with family and more privacy. They also stated other benefits toward HHD, such as minimized wasted time due to reduced travel time (95\%) and better well-being (95\%). On the other hand, the most common perceived barriers to HHD by healthcare professionals were as follows: lack of appropriate home environment for hemodialysis (90\%), the need of family support in order to maintain optimal treatment process $(80 \%)$, needle phobia (55\%) and safety problems due to intradialytic hemodynamic and metabolic changes (50\%). The results of this study are similar to those of previous studies [1,10-13].

This study has some limitations because of its design, and sample size. The results therefore cannot be generalized to all Turkish healthcare professionals. Better understanding of the beliefs and attitudes about HHD of healthcare professionals can help support them more effectively.

\section{Acknowledgment}

The authors thank all the patients who participated in this study.

\section{References}

1. Kara B (2016) The beliefs and experiences about home hemodialysis: a review of the current evidences. Turk Neph Dial Transpl 25(Suppl 1): $17-23$.

2. Perl J, Chan CT (2009) Home hemodialysis, daily hemodialysis, and nocturnal hemodialysis: core curriculum. Am J Kidney Dis 54(6): 1171-1184.
3. Agar JW, Hawley CM, Kerr PG (2011) Home hemodialysis in Australia and New Zealand: how and why it has been successful. Semin Dial 24(6): 658-663.

4. Bolgg A, Hyde C (2006) Enhancing lifestyle through home haemodialysis. J Ren Care 32(4): 179-182.

5. Cardone KE, Manley HJ, Grabe DW, Meola S, Hoy CD, et al. (2011) Quantifying home medication regimen changes and quality of life in patients receiving nocturnal home hemodialysis. Hemodial Int 15(2): 234-242.

6. Pipkin M, Eggers PW, Larive B, Rocco MV, Stokes JB, et al. (2010) Recruitment and training for home hemodialysis: experience and lessons from the nocturnal dialysis trial. Clin J Am Soc Nephrol 5(9): 1614-1620.

7. Rioux JP, Marshall MR, Faratro R, Hakim R, Simmonds R, et al. (2015) Patient selection and training for home hemodialysis. Hemodial Int 19(Suppl 1): S71-79.

8. Pauly RP, Gill JS, Rose CL, Asad RA, Chery A, Pierratos A, et al. (2009) Survival among nocturnal home haemodialysis patients compared to kidney transplant recipients. Nephrol Dial Transplant 24(9): 29152919.

9. Susantitaphong P, Koulouridis I, Balk EM, Madias NE, Jaber BL (2012) Effect of frequent or extended hemodialysis on cardiovascular parameters: a meta-analysis. Am J Kidney Dis 59(5): 689-699.

10. Tong A, Palmer S, Manns B, Craig JC, Ruospo M, et al. (2012) Clinician beliefs and attitudes about home haemodialysis: a multinational interview study. BMJ Open 2(6): pii: e002146.

11. Tennankore KK, Hingwala J, Watson D, Bargman JM, Chan CT (2013) Attitudes and perceptions of nephrology nurses towards dialysis modality selection: a survey study. BMC Nephrol 14: 192

12. Ludlow MJ, George CR, Hawley CM, Mathew TH, Agar JW, et al. (2011) How Australian nephrologists view home dialysis: results of a national survey. Nephrology 16(4): 446-452.

13. Jayanti A, Morris J, Stenvinkel P, Mitra S (2014) Home hemodialysis: beliefs, attitudes, and practice patterns. Hemodial Int 18(4):767-776.

Your next submission with Juniper Publishers
will reach you the below assets
- Quality Editorial service
- Swift Peer Review
- Reprints availability
- E-prints Service
- Manuscript Podcast for convenient understanding
- Global attainment for your research
- Manuscript accessibility in different formats
( Pdf, E-pub, Full Text, Audio)
- Unceasing customer service
Track the below URL for one-step submission
https://juniperpublishers.com/online-submission.php

